\title{
COVID-19: Putting Stock Markets Back on Recovery Among the Crude Oil Producing Economies
}

Solomon A. Olakojo', Abayomi T. Onanuga ${ }^{2}$, and Olaronke T. Onanuga ${ }^{3}$

ABSTRACT

\begin{abstract}
COVID-19 poses an unprecedented threat to components of global business cycles including stock markets, industrial production and employment. This study investigated its impact on stock markets of 24 oil producing COVID-19-hit economies in North America, South America, Europe, Asia, Oceania and Africa. It examined the nature of asymmetry in the business cycles of the sampled countries and the impact of COVID-19 on the asymmetry. Switching regression techniques were estimated with data covering the period from October 1, 2019 to April 14, 2020. The results confirmed the presence of negative asymmetry in stock market cycles in $54.2 \%$ of the sampled countries, out of which $38.5 \%, 46.2 \%$ and $15.4 \%$ are high, middle and low-middle income countries, respectively. This is significantly connected to the COVID-19 pandemic for $29.2 \%$ of the sample. The expected duration of being in the state of low stock market performance, due to COVID-19, reduces with levels of countries'income, if regimes are dependent. Opposite was observed if regimes are independent. Hence, the negative impact of COVID-19 on stock markets in lower-income countries will linger compared to higher-income countries. Reducing COVID-19-associated risks will go a long way to revive investors' confidence in the market and help to restart the engine of economic recovery in the sampled countries.
\end{abstract}

KEY WORDS: $\quad$ COVID-19, stock market, business cycles, crude oil producing economies.

JEL Classification: E32, I15, Q41.

'Lecturer, Department of Economics, University of Ibadan, Ibadan, Oyo State, Nigeria

${ }^{2}$ Senior Lecturer, Department of Economics, Olabisi Onabanjo University, Ogun State, Nigeria

${ }^{3}$ Lecturer, Department of Economics, KolaDaisi University, Ibadan, Oyo State, Nigeria.

Research Associate, Centre for Economic Policy and Development Research (CEPDeR), Covenant University, Ota, Ogun State, Nigeria

\section{Introduction}

A novel infectious Coronavirus disease (abbreviated as COVID-19) associated with a severe acute respiratory syndrome surfaced in Wuhan, China in December 2019. It has since spread to 210 Countries and Territories around the world with a total of over $2,276,547$ confirmed cases and a death toll of over 156,141 deaths (Worldometer, 2020). Besides the tragic health hazards and human consequences of the COVID-19 pandemic, the economic uncertainties, and disruptions to global value chains that have

Correspondence concerning this article should be addressed to: Solomon A. Olakojo, Department of Economics, University of Ibadan, Ibadan, Oyo State, Nigeria. E-mail: solomonolakojo@gmail.com resulted represents a huge cost to the global economy. A preliminary downside scenario of the United Nations Trade and Development Agency (UNCTAD) sees a US $\$ 2$ trillion shortfall in global income with a US $\$ 220$ billion hit to developing countries (excluding China) and a global recessionary threshold below 2.5\% (United Nations Conference on Trade and Development [UNCTAD], 2020).

Crude oil is an important input in the global value chains. COVID-19 outbreak is occurring at a time when the oil market is already weak due to oil price war between Russia and the OPEC cartel. The existing pressure in the oil market coupled with the slowdown in the global economy as a result of COVID-19 resulted in significant decline in global demand for 
oil, leading to an unprecedented fall in oil price below the experience of the 2007-08 global recession. Hence, COVID-19 creates additional burden for the oil producing economies with undesired potential effects on the global value chains.

Unlike other epidemics, such as Severe Acute Respiratory Syndrome (SARS) and Ebola, no sector is completely spared of COVID-19 impact. However, the impacts on the global aviation, tourism and associated services such as transportation, hotels and hospitality are more significant due to declining demand for these services and global lockdown. The estimates of COVID-19 impact on scheduled international passenger traffic during first half of 2020 , compared to originally-planned indicates an overall reduction of $47 \%$ to $58 \%$ of seats offered by airlines. The biggest impact is expected Europe and Asia/Pacific, followed by North America and Middle East (International Civil Aviation Organization of the United Nations [ICAO], 2020).

It is clear that COVID-19 has negatively affected the global business cycles in the form of declined stock market performance, reduced industrial productivity, and increasing unemployment. These are leading, coinciding, and lagging variables, respectively in the discussion and construction of business cycles (Chauvet, 2001, Olakojo, 2018). That is, poor stock market performance is a signal for the onset of business cycles downturn, reduced industrial productivity is evidence of presence of business cycles downturn, while rising unemployment and accumulated inventory are consequences of business cycles downturn. For instance, while the global stock markets plummeted early in the first quarter of 2020, The United Nations Industrial Development Organisation (UNIDO) reported a huge decline in the global industrial output, with manufacturing production slumping by $6.0 \%$ in the first quarter of 2020 compared to corresponding quarter's output in 2019 (United Nations Industrial Development Organisation [UNIDO], 2020). Also, The International Labour Organisation (ILO) estimated percentage drop in aggregate working hours compared to the pre-COVID-19 baseline (4th quarter 2019 , seasonally adjusted) to be $4.5 \%$ globally (International Labour Organisation [ILO], 2020).
The issue that remains unclear is the time it will take countries' business cycles to get back on recovery path and factors that may propel such recovery. Using stock market as a proxy for business cycles, this study investigated the timing of stock markets recovery among the sampled economies in global North and South. It compared the recovery time of developed countries with the developing economies with the aim of assessing the factors responsible for differences in stock markets recovery time. It equally checked the nature of asymmetry in the stock markets dynamics of sampled developed and developing countries.

The rest of the paper is organised as follows: besides the introductory section where the problems and objectives of the study are stated, section two looks at literature review focusing on conceptualisation of business cycles on one hand, and link between pandemic and business cycles on the other hand as well as review of previous related studies. In section three, methodology and data sources are presented. Section four presents the results, while chapter five concludes the study with policy recommendations.

\section{Literature Review}

\subsection{Theoretical Literature}

For conceptual calcification, COVID-19 of 2019 belongs to the same family of coronaviruses that cause SARS (severe acute respiratory syndrome) and MERS (Middle East respiratory syndrome) that appeared in 2003 and 2012, respectively. While the three have similar origin and transmission mechanisms, SARS and MERS occurrence are mostly in China and Middle East with other occasional hotspots. Since SARS and MERS occur at the level of a region or community, they are defined as epidemic by the World Health Organisation (WHO). However, this is not the case with COVID-19 which is prevalent throughout the entire world, making it qualified as a pandemic, and can also spread in the community more easily than MERS and SARS (Petrosillo et al., 2020). Hence, COVID-19 can only be compared with the 1918 influenza pandemic in recent history in terms of severity of infections, fertility rate and economic devastation.

Economic fluctuations, caused by health or other economic issues, are characterised with uneven distribution across economic activities. Hence, the problem of measuring the aggregate state of the economy with respect to 
business cycles may not be straightforward. The National Bureau of Economic Research (NBER) approach to business cycles construction grouped economic series into three; leading, coinciding and lagging series. The leading series, on the average, were from one to ten months ahead of the reference revival, while the lagging series were from one to twelve months behind. Among the leading variables are the number and value of shares sold in New York stock exchange and average hours worked per week in manufacturing. The coinciding variable is physical value of business activities and 'laggers' are total factory pay rolls and ninety-day time money rate.

Given the forward-looking behaviour of stock market investors, studies have explored the possibility of predicting business cycle turning points using stock markets and financial variables (Diebold \& Rudebusch, 1991; Hamilton \& Lin, 1996; Estrella \& Mishkin, 1998; Chauvet, 2001; Muchaonyerwa \& Choga, 2015; Adam and Merkel, 2019). The key finding of these studies is that stock markets predict business cycles turning points. However, stock market is also prone to signalling false alarms as a leading indicator in business cycles; but the proportion of false positive alarm is low (Siegel, 1991; Haltmaier, 2008; Fendel, Mai \& Mohr, 2019). Hence, stock market fluctuations lead the business cycle and seem to be generated from expectations about changes in future economic activity (Chauvet, 2001).

There is a connection between pandemic and business cycles- a recurring phase of expansion and recession in the overall level of economic activity. Traditionally, business cycles have two sides of causes: the demand side (monetary policy, consumer expectations, credit cycles, changes in real wages and exchange rate movement) and the supply side (technology shocks, changes in productivity, and inventory cycles). Pandemics cause disruption to global value chains, stock markets, industrial production and accumulation of inventory is more relevant to the supply side of business cycles. While some business cycles may be symmetric, having a cycle with zero mean (that is, the period of business cycles collapse is equal to the period of business cycles boom), some may actually be asymmetric- characterised with a longer boom or a longer doom. The reason for the difference in the behaviour of business cycles is rooted in the underlying causes. Periodic pandemic affects the whole economy and brings output below the trend level at which it would have operated under normal health is one of the causes of asym- metric business cycles (Morley, 2019). War is another. However, Zarnowitz (1985) did not categorise these types of cycles into business cycle because they do not themselves produce the recurrent sequences of expansions and contractions. That is, business cycles are mainly generated by the internal economic mechanisms and exposure to related potential relevant external shocks. Nevertheless, evidence for business cycle asymmetry supports the idea that recessions are like health shocks which pull the economy further below trend than expansions lift the economy above trend (Morley, 2019). Hence, while economic fundamentals are more relevant to symmetric business cycles other factors such as disease outbreak and war characterise asymmetric business cycles.

\subsection{Empirical Literature}

Studies have examined the relationship between stock market and business cycles. For instance, Hamilton and Lin (1996) investigated why stock market is much more volatile in some times than others in the USA. The conclusion was that economic recession accounts for about $60 \%$ of variances of stock returns. In other words, stock return and recession are closely related. Also, Chauvet, (2001) examined the dynamic relationship between stock market fluctuations and the business cycle for the USA. The findings found that stock market factor is a leading indicator of business cycles. Estrella and Mishkin (1998) examined the performance of various financial variables including stock prices in prediction USA recession. The study found that the yield curve spread and stock prices have a useful role in macroeconomic prediction.

Health challenges in the form of either pandemic or epidemic have economic consequences. For instance, Baker et al. (2020) underscored the unprecedented impact of the COVID-19 pandemic on the U.S. stock market compared to 1918-19 influenza pandemic and other pandemics such as 1957-58 H2N2 and 1968 H3N2 virus. However, no previous episodes of pandemic in the past 120 years can be compared with COVID-19 which is characterised with an extremely high frequency of large daily stock market moves (Baker et al., 2020).

Recently, the impacts of other epidemics such as SARS and MERS also have also been examined in their respective epicentres. For example, Qiu et al. (2018) examined the impacts of SARS in 2003 and H7N9 in 2013 in China and concluded that both SARS and H7N9 have had an impact on China, causing significant negative impacts on 
health, the economy, and even national and international security. However, the social and economic impacts of H7N9 were not as serious as in the case of SARS because of the more effective response to H7N9. Also, KeoghBrown and Smith (2008) analysed the macro-economic impact of the 2003 SARS outbreak. The results showed that the scale of the SARS impact on affected economies was far smaller than suggested by contemporary media reports and model estimates. Lee and McKibbin (2004) estimated the global economic cost of SARS. The findings suggested that the cost in 2003 of SARS for the world economy as a whole are close to \$US 40 billion in the case where SARS is expected to be a single event, versus costs of close to \$US 54 billion in 2003 if SARS is expected to recur (this does not include the actual costs of later years if in fact SARS did recur). Further, Joo eta al. (2019) investigated the economic impact of the 2015 MERS outbreak on the Republic of Korea's tourism-related industries. The results showed that the MERS outbreak cost US $\$ 2.6$ billion tourism loss. The estimated losses in the accommodation, food and beverage service, and transportation sectors associated with 2.1 million noncitizen visitors decline were US \$542 million, US \$359 million, and US \$106 million, respectively. Besides, Jung and Sung (2017) examined the influence of the MERS outbreak on online and offline markets for retail sales in Korea. The basic outcome of the study was that offline sales of electronic goods declined by $7.9 \%$, while online sales increased by $7.03 \%$.

On the impact of SARS on stock markets, Chen et al. (2007) examined the impact of the SARS outbreak on Taiwanese hotel stock price movements. The results indicated that Taiwanese hotel stocks showed significantly negative cumulative mean abnormal returns linked to the impact of SARS outbreak on hotel stock performance. In a related study, Chen et al. (2018) analysed the impact of SARS epidemic on the integration of Asian stock markets. The outcomes of the study support the existence of a time-varying cointegration relation in the aggregate stock price indices, and that the SARS epidemic did weaken the long-run relationship stock market integration between China and the four other markets including Hong Kong, Taiwan, Singapore and Japan.

While the total impact of the more recent COVID-19 pandemic on any economy cannot be fully appreciated yet, its effects on stock markets have been examined. For instance, Liu et al (2020) evaluated the short-term impact of the coronavirus outbreak on 21 leading stock market indices in major affected countries, including Japan, Korea, Singapore, the USA, Germany, Italy, and the UK. The study found that countries in Asia experienced more negative abnormal returns as compared to other countries. The panel fixed effect regressions also supported the adverse effect of COVID-19 confirmed cases on stock indices abnormal returns. This was largely due to investors' pessimistic sentiment on future returns and fears of uncertainties. Besides, He et al. (2020), attempted to explore the direct effects and spill-overs of COVID-19 on stock markets using daily return data from stock markets in the People's Republic of China, Italy, South Korea, France, Spain, Germany, Japan and the United States of America. The results showed that COVID-19 has a negative but short-term impact on stock markets of sampled countries and that the impact of covid-19 on stock markets has bidirectional spill-over effects among Asian, European and American countries.

Also, Baker et al (2020) evaluated potential explanations for the unprecedented stock market reaction to the COVID-19 pandemic. The results suggested that government restrictions on commercial activity and voluntary social distancing, operating with powerful effects in a service-oriented economy, are the main reasons the U.S. stock market reacted so much more forcefully to COVID-19 than to previous pandemics in 1918-19, 1957-58 and 1968. In addition, Sansa (2020), applied a simple regression model to investigate the impact of the COVID-19 on the Financial Markets during the period from dated 1st March 2020 to 25th march 2020 in China and USA. The study revealed that there is a positive significant relationship between the COVID-19 confirmed cases and all the financial markets (Shanghai stock exchange and New York Dow Jones) in China and USA. That is, COVID-19 had a significant impact on the financial markets in the two countries.

The above review shows that COVID-19 pandemics and other related epidemics such as SARS and MERS have had a significant negative impact on the global economies and stock markets. However, among the studies that investigated the effects of past coronavirus infectious diseases on the stock markets, the stock market recovery timing and factors that may propel such recovery have not been given adequate attention especially across countries of different income levels, including African countries. Also, the nature of asym- 
metry in the stock markets dynamics across developed and developing countries due to COVID-19 health shocks is yet to be fully examined. This study addressed these issues. Again, the focus of this study is on COVID-19-hit crude oil producing economies because COVID-19 pandemic has disrupted the global supply chains of which crude oil is a major element, thus created additional burden for these economies. Hence, the study fills the gap in empirical literature and becomes relevant in policy debates of the need for proactive moves that can minimise asymmetric output gaps.

\section{Methodology and Data}

The study utilises the Markov and simple switching regression techniques to capture the impact of COVID-19 on stock markets of the sampled economies. These approaches are relevant to test if switch in stock market is due to COVID-19 outbreak, and the timing of rebound among the sampled economies. Markov switching AR models, unlike dynamic Markov switching, allow a gradual adjustment after the process changes state and are suitable and often used to model quarterly and lower-frequency data. We start by assuming an autoregressive switching regression that allows for different behaviour (structural break) in one sub-sample (regime) to another as:

$Q_{j t}=x_{j t}^{\prime} \beta S_{t}+u_{t}, \quad t=1, \ldots T$

$u_{t} \sim N I D\left(0, \delta_{S t}^{2}\right)$

$Q_{j t}$ is daily stock price index and $x_{t}$ is a $(\mathrm{kx} 1)$ vector of explanatory variables which includes lag values of $Q_{t}$ in the autoregressive specification. Other explanatory variables are daily average crude oil price (to proxy for market risks), and COVID-19 daily infections. Sharp decline in oil prices implies risk to the investment in stock market as the economy is seen as less viable, especially for countries relying heavily on crude oil. $S_{t}$ is a discrete state variable which is unobserved and are assumed to evolve according to a Markov chain with transition probabilities: $P\left(S_{t}=i \backslash S_{t-1}=j, z_{t}\right)=P_{i j}\left(z_{t}\right)$. The two unobserved state variables are coefficient parameter vector: $\beta S_{t}=\beta_{0}\left(1-S_{t}\right)+\beta_{1}\left(S_{t}\right)$ and error variance: $\delta^{2} S_{t}=\delta^{2}{ }_{0}\left(1-S_{t}\right)+\delta^{2}{ }_{1}\left(S_{t}\right)$. Hence, under regime $1(0)$, the coefficient parameter vector is $\beta_{1}(0)$ and error variance $\sigma_{1}^{2}(0)$.
Following the popular two-regime case in empirical literature, $x_{t}$ is a series which involves two Autoregressive (AR (1)) specifications:

$Q_{i j t}= \begin{cases}\propto_{0}+\gamma Q_{i j t-1}+\epsilon_{i t}, & S_{t}=0 \\ \propto_{0}+\propto_{1}+\gamma Q_{i j t-1}+\epsilon_{i t}, & S_{t}=1\end{cases}$

$Q_{t}$ is a stationary $\operatorname{AR}(1)$ process with mean $\propto_{0} / 1-\gamma$ when $S_{t}=0$, and it switches to another stationary $\operatorname{AR}(1)$ process with mean $\left(\propto_{0}+\propto_{1}\right) / 1-\gamma$ when St changes from 0 to 1 . As long as $\propto_{1} \neq 0$, this model admits two dynamic structures at different levels, depending on the value of the state variable $S_{t}$. In this case, $Q_{t}$ are governed by two distributions with distinct means, and St determines the switching between these two distributions (regimes). Two Regime-Markov chain has two parameters which can be stated as:

$P=\left|\begin{array}{ll}p\left(S_{t}=0 / S_{t-1}=0\right. & p\left(S_{t}=1 / S_{t-1}=0\right. \\ p\left(S_{t}=0 / S_{t-1}=1\right. & p\left(S_{t}=1 / S_{t-1}=1\right.\end{array}\right|$

Equation 3 can be represented in transition probabilities as:

$P=\left|\begin{array}{ll}p_{00} & p_{01} \\ p_{10} & p_{11}\end{array}\right|$

Hence, there are two possible states: state 1 (state of trough in stock market cycles) and state 2 (state of peak in stock market cycles). The possible transition probabilities given this two states are: (a) probabilities of transiting to trough in stock market cycles in the next period given that the current state is in trough $\left(\mathrm{P}_{00}\right)$; (b) probabilities of transiting to trough in stock market cycles in the next period given the current peak state of stock market cycles $\left(\mathrm{P}_{01}\right)$, which represents contraction in business cycles; (c) probabilities of transiting to peak in stock market cycles in the next period given that the current state is in trough $\left(\mathrm{P}_{10}\right)$, which implies expansion; and (d) probabilities of transiting to peak in the next period given that the current state is peak $\left(\mathrm{P}_{11}\right)$. The $\mathrm{P}_{00}$ and $\mathrm{P}_{11}$ are state of deceleration and acceleration in stock market cycles, respectively.

As with the Markov autoregressive regime specification in Equation 3 the presence of lagged states in the simple autoregressive switching specification also complicates the dynamics in the estimations but handles a dimensional state variable representing 
current and lag states. In other words, simple switching regression restricts Markov switching model with transition probabilities that do not depend on the origin regime such that:

$P\left(s_{t}=\frac{j}{s_{t-1}}=i\right)=P_{i j}(t)=P_{j}(t)$

So that the row of the transition matrix is identical to that of Markov in Equation 4:

$P=\left|\begin{array}{ll}p_{0} & p_{1} \\ p_{0} & p_{1}\end{array}\right|$

Hamilton filter and Kim smoother are then applied to the restriction in Equation 6 to obtain the one-step ahead, likelihood, filtered and smoothed values.

In terms of sequencing, the study confirms the stationarity of the time series to ensure that the series are not $\mathrm{I}(2)$. Besides the use of state means and variances to test for the overall switch (means and volatility shifts) in stock market cycles and their asymmetries (See Kaufmann, 2002), the study also confirms the switch effect of COVID-19 and oil prices on the business cycles of the sampled countries. The hypotheses of independent states are tested using standard likelihood-based Wald test, while Akaike info criterion (AIC) criterion was used to establish adequate AR terms.

\subsection{Data and Sampling}

This study utilized daily data on stock market price index, oil prices, and COVID-19 cases between October 1 2019 and April 14 2020. The justification for the coverage (to include a quarter before COVID-19) is to have adequate data points covering the pre-and COVID-19 era. The sampling comprises of 24 COVID-19 mostly hit major oil producing economies in each of North America (USA, Canada and Mexico), South America (Brazil, Chile, Ecuador, Peru and Columbia) Europe (United Kingdom, Italy, France, Spain and Germany), Asia (China, India, Turkey, Japan, and South Korea), Africa (South Africa, Nigeria, Tunisia, and Morocco), and Oceania (Australia and New Zealand). COVID-19 daily cases data was sourced from Worldometer (2020). Daily Brent crude oil price (United States Energy Information Administration [US EIA], 2020) is used for Europe, Africa, and Asia, because petroleum production flowing from these regions to the West tends to be priced relative to this oil, which makes it a benchmark.
West Texas Intermediate (WTI) is used for North and South America. This is also regarded as Texas light sweet (US EIA, 2020). This is unweighted average of the daily closing spot prices for these crude oil prices over the specified time period. This data is sourced from USA Energy Information Administration (EIA). Daily stock market index data was obtained from the investing.com (a global financial portal which offers real time quotes, portfolio, financial news, live stock market data and more).

\section{Results and Discussion}

\subsection{Descriptive Analysis}

Pressure on the global oil market started around January 9, 2020 when the oil prices started experiencing downward movement (Figure 1). This development was traceable to oil price war between Russia and the OPEC cartel. While there was a little rebound around February, the global oil market fell deeper in early March, 2020 when COVID-19 started hitting hard on countries around the world. There was a little rebound in early April but this was not sustainable.

The distribution of COVID-19 cases and stock price indexes across the sampled countries presented in Table 1 and 2 show significant skewness, confirmed by Jarque-Bera statistics. While COVID-19 shows positive skewness, it is negative for stock market index except for China and Turkey (Table 2). This indicates that the tail on the right side of COVID-19 distribution is longer. This is not the case with stock prices with tail extended towards the left. The implication of this is that stock performances in the sampled countries have nosedived in the recent time while COVID-19 cases has risen significantly in all sampled countries. Hence, the series are not normally distributed. This justifies the use of switching regression techniques which allows for structural break in one sub-sample (regime).

Further, Table 1 shows that COVID-19 cases is highest in the USA and lowest in Nigeria. Overall, COVID-19 cases follow the level of economic development. The cases are higher among the highincome countries than lower income countries. This has been attributed to the level of health infrastructural development and ability to test for the infections. In the case of stock market (Table 2), the poor- 


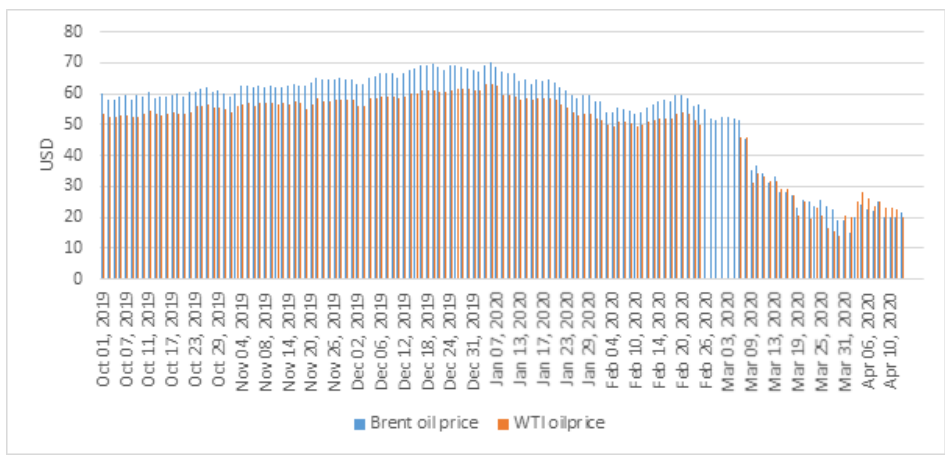

Figure 1. Crude oil prices.

Source: USA energy information Administration (EIA)

est performance, given the recent climate, is noticed with Columbia followed by South Africa and Tunisia. China and Turkey stock markets are less affected.

\subsection{Unit Root Test}

Traditional unit root test ignores the possibility of breaks in the series. Hence, stationarity properties of the series (accounting for structural breaks) across the sampled countries are presented in Table 3 ( $\mathrm{a}$ and $\mathrm{b}$ ). The general noticeable trend is that Brent oil price is not stationary while WTI is stationary at level. Accounting for structural break, stock indexes are stationary (that is, $\mathrm{I}(0)$ ) for UK, USA, China, Turkey, Japan, Nigeria, Morocco, Chile, Peru and New Zealand but non-stationary at level for others. Similar mixed trends were noticed with COVID-19 cases. The series of COVID-19 cases is non-stationary at level for Germany, Spain, USA, Japan, Nigeria, Australia and New Zealand. All non-stationary series are first differenced stationary. For the stationary series, it implies that any shock to the series will have a temporary effect, making them more predictable at level. Oil price exhibited breaks before COVID-19 was pronounced a pandemic across the sampled countries, in late February and early March. This suggests that there has been downward pressure on oil mar- ket before the COVID-19 pandemic. Breaks in stock price indexes cut across different times, while COVID-19 cases exhibited most breaks in late March and early April. This shows that stock market responses may be due to crude oil price crash, COVID-19 and any other structural issue or risk factors. This will be unravelled in the subsequent section.

\subsection{Switching Estimates of Business Cycles}

As previously indicated, the study specifies a two-state Markov switching model in which the mean and variance of stock market index is subject to regime switching, and where the errors follow a regime-invariant $\mathrm{AR}(1)$ process. However, implementation is based on either a Markov model or a simple-switching model (Table 4-6). van Norden and Vigfusson (1996) noted that, the relationship between current period's state and the previous period's state determines the set of procedures to use. While the states are dependent in firstorder Markov model, they are independent in simple switching model. Hence, the choice of either of the two depends on; (a) state dependency, by allowing switch in the parameters of the explanatory variables including state parameters and test states dependency; and (b) stationarity of estimated AR processes. The former is a necessary condition, while the latter is a sufficient 
Table 1. COVID-19 Cases

\begin{tabular}{|c|c|c|c|c|c|c|c|c|c|c|c|c|}
\hline & France & Germany & Italy & Spain & UK & Canada & Mexico & USA & China & India & Turkey & Japan \\
\hline Mean & 11805.4 & 13416.1 & 19166.0 & 17601.9 & 7146.3 & 2191.9 & 353.1 & 49037.1 & 30513.2 & 756.1 & 4446.0 & 690.9 \\
\hline Maximum & 147969 & 141397 & 172434 & 190839 & $1 \mathrm{E}+05$ & 31927 & 6297 & 709735 & 82692 & 14352 & 78546 & 9787 \\
\hline Minimum & 0 & 0 & 0 & 0 & 0 & 0 & 0 & 0 & 0 & 0 & 0 & 0 \\
\hline Skewness & 2.9 & 2.6 & 2.3 & 2.6 & 3.4 & 3.2 & 3.7 & 3.2 & 0.5 & 3.9 & 3.7 & 3.4 \\
\hline Kurtosis & 10.6 & 8.4 & 6.9 & 8.6 & 13.5 & 12.4 & 16.6 & 12.4 & 1.3 & 17.9 & 15.9 & 14.3 \\
\hline Jarque-Bera & 546.4 & 336.9 & 214.1 & 347.5 & 919.7 & 763.2 & 1430.1 & 763.9 & 21.0 & 1667.5 & 1306.6 & 1017.9 \\
\hline Probability & 0 & 0 & 0 & 0 & 0 & 0 & 0 & 0 & 0.0 & 0 & 0 & 0 \\
\hline \multirow[t]{2}{*}{ Observations } & 142 & 142 & 142 & 142 & 142 & 142 & 142 & 142 & 132 & 142 & 143 & 140 \\
\hline & South Korea & Nigeria & Morocco & South Africa & Tunisia & Brazil & Chile & Columbia & Ecuador & Peru & Australia & New Zealand \\
\hline Mean & 2247.9 & 28.5 & 155.2 & 210.1 & 64.4 & 1873.3 & 621.9 & 213.4 & 521.8 & 617.8 & 670.7 & 118.7 \\
\hline Maximum & 10635 & 493 & 2564 & 2783 & 864 & 33682 & 9252 & 3439 & 8225 & 13489 & 6533 & 1409 \\
\hline Minimum & 0 & 0 & 0 & 0 & 0 & 0 & 0 & 0 & 0 & 0 & 0 & 0 \\
\hline Skewness & 1.3 & 3.5 & 3.4 & 2.9 & 3.0 & 3.7 & 3.3 & 3.5 & 3.5 & 4.3 & 2.5 & 2.9 \\
\hline Kurtosis & 2.8 & 15.1 & 14.2 & 10.5 & 10.9 & 16.7 & 13.1 & 15.0 & 15.2 & 21.5 & 7.8 & 10.0 \\
\hline Jarque-Bera & 37.0 & 1129.8 & 995.4 & 515.2 & 571.3 & 1372.3 & 839.7 & 1085.9 & 1106.6 & 2482.6 & 280.5 & 488.9 \\
\hline Probability & 0 & 0 & 0 & 0 & 0 & 0 & 0 & 0 & 0 & 0 & 0 & 0 \\
\hline Observations & 136 & 138 & 140 & 138 & 138 & 135 & 138 & 134 & 133 & 143 & 138 & 141 \\
\hline
\end{tabular}

condition. In other words, the model in which the AR roots lie within the unit circle (inverted AR roots $<1$ ), is preferred because it determines the long run stability and convergence of the model. In the regime-switching estimated models, the observable dependent variable's behaviour is assumed to be state-dependent, while the state (which itself is unobservable) determines the process that generates the dependent variable.

The hypotheses of state-independence are tested using standard likelihood-based Wald test. Tables 4-6 show that not all the countries sampled satisfied the necessary condition in shift-parameter (that is, in mean) but they all satisfied the sufficient condition in state variances. That is, the state variances are independent across states given the significant $t$-statistics tests across estimations. The null hypotheses that volatilities are the same between regimes are rejected (Table 4 to 6), except for Morocco (Table 6). These are pointer that, overall, the sampled countries have experienced significant asymmetric shifts in stock market cycles. However, periods of stock markets downturn are relatively large and negative in some economies than others (see hypotheses testing in Table 2-6). In addition, a(symmetric) to stock market cycles varied in explanatory variables.
The coronavirus-hit oil producing sampled countries are grouped based on their level of income following World Bank's countries income groups. Allowing switch in the parameters of the explanatory variables showed varied results in different regimes. Among the high-income countries (in Table 4), changes in crude oil price generates significant shift and asymmetry in stock index in Spain, Canada, USA and Australia. The periods of business cycles downturn due to oil price movement are relatively large and negative among these economies except for Australia (see the expected duration and hypothesis testing in Table 4). COVID-19 is more relevant to stock market asymmetry of all sampled high-income economies except in Germany, Spain, Italy, UK, and Australia (Table 4). Also, there is a considerable state dependence in the transition probabilities with higher probability of remaining in the origin regime among the developed countries estimated with Markov switching model unlike those estimated with simple switching model (see transition probabilities in Table 4). In addition, increased COVID-19 cases have significant negative effects among the models estimated with simple switching unlike models estimated with Mar- 
Table 2. Stock Market Index

\begin{tabular}{|c|c|c|c|c|c|c|c|c|c|c|c|c|}
\hline & France & Germany & Italy & Spain & UK & Canada & Mexico & USA & China & India & Turkey & Japan \\
\hline Mean & 6672.6 & 8695.2 & 23857.9 & 8862.2 & 3853.9 & 16236.0 & 41978.1 & 3041.0 & 10313.3 & 38228.0 & 110958.0 & 3500.2 \\
\hline Maximum & 7412.6 & 9876.1 & 27675.1 & 10083.6 & 4257.9 & 17944.1 & 45902.7 & 3386.2 & 11856.1 & 41952.6 & 129730.3 & 3965.1 \\
\hline Minimum & 4612.0 & 5496.7 & 16286.4 & 6107.2 & 2727.9 & 11228.5 & 32964.2 & 2237.4 & 9474.8 & 25981.2 & 87677.9 & 2783.8 \\
\hline Skewness & -1.3 & -1.2 & -1.2 & -1.3 & -1.3 & -1.4 & -1.3 & -1.0 & 0.7 & -1.4 & 0.0 & -0.7 \\
\hline Kurtosis & 3.2 & 3.1 & 3.0 & 3.1 & 3.1 & 3.8 & 3.3 & 3.4 & 2.3 & 3.5 & 1.9 & 2.4 \\
\hline Jarque-Bera & 38.7 & 36.5 & 34.4 & 39.8 & 39.0 & 51.1 & 43.4 & 26.9 & 12.0 & 49.6 & 6.8 & 14.3 \\
\hline Probability & 0.0 & 0.0 & 0.0 & 0.0 & 0.0 & 0.0 & 0.0 & 0.0 & 0.0 & 0.0 & 0.0 & 0.0 \\
\hline \multirow[t]{2}{*}{ Observations } & 142 & 142 & 142 & 142 & 142 & 142 & 142 & 142 & 132 & 142 & 143 & 140 \\
\hline & South Korea & Nigeria & Morocco & South Africa & Tunisia & Brazil & Chile & Columbia & Ecuador & Peru & Australia & New Zealand \\
\hline Mean & 2054.8 & 26204.9 & 11473.0 & 53884.6 & 6899.4 & 103058.6 & 22443.6 & 1522.6 & 1375.0 & 122.6 & 6566.3 & 1843.5 \\
\hline Maximum & 2267.3 & 29710.6 & 12633.6 & 59001.9 & 7204.4 & 119527.6 & 26136.8 & 1676.5 & 1426.5 & 151.0 & 7255.2 & 2013.7 \\
\hline Minimum & 1457.6 & 20669.4 & 8987.9 & 37963.0 & 6116.2 & 63569.6 & 14685.3 & 894.0 & 1321.0 & 61.0 & 4564.1 & 1398.9 \\
\hline Skewness & -1.4 & -0.9 & -1.2 & -1.6 & -1.6 & -1.2 & -1.2 & -1.7 & -0.5 & -1.0 & -1.4 & -1.2 \\
\hline Kurtosis & 4.2 & 3.1 & 3.2 & 4.4 & 4.3 & 3.0 & 3.7 & 4.3 & 1.8 & 2.6 & 3.6 & 3.9 \\
\hline Jarque-Bera & 52.7 & 19.4 & 34.8 & 70.5 & 71.5 & 31.3 & 37.9 & 72.0 & 12.8 & 26.4 & 47.9 & 38.6 \\
\hline Probability & 0.0 & 0.0 & 0.0 & 0.0 & 0.0 & 0.0 & 0.0 & 0.0 & 0.0 & 0.0 & 0.0 & 0.0 \\
\hline Observations & 136 & 138 & 140 & 138 & 138 & 135 & 138 & 134 & 133 & 143 & 138 & 141 \\
\hline
\end{tabular}

kov switching, except Japan, and New Zealand, with significant covid-19 negative effect in regime 2 . These are expected because simple switching model is stateindependence, suitable for short-run effects of COVID-19, while Markov captures the overall behaviour of stock market cycles taking the previous state into account. Meanwhile, a rebound in crude oil prices will propel stock market improved performance in France, Spain, Italy, Canada, South Korea, USA and Australia.

The expected durations of being in a state of high or low business cycle equally vary between Markov and simple switching models. While Markov switching's expected durations are longer, capturing dynamics between states, simple switch models are not. Also, the gap between the expected duration explains the extent of asymmetric in the business cycles. The asymmetry is largest for Germany with periods of stock market downturn longer and negative (that is, long falling before a rise). For UK, Australia and New Zealand, stock market asymmetric is also large but downturn periods will be relatively shorter and positive (that is, long rising from low to high stock market cycles).

Overall, the pandemic is an important factor contributing to asymmetric effect in stock market cycles among the sampled developed countries but the impact varies from one country to another. This corroborates Morley (2019).

Among the upper-middle income countries (Table 5), asymmetric stock market cycles is explained by changes in oil prices for Brazil, China, Ecuador, and Peru. However, asymmetry is negative for Brazil and Peru. That is, the expected duration of being in state of low stock market cycles, caused by oil price changes, will exceed that of high stock market cycles. The asymmetric stock market cycles among the uppermiddle income are also explained by the occurrence of COVID-19 cases in Brazil, Ecuador, Peru, and Turkey. While the asymmetric is negative for Brazil and Peru, it is positive in Ecuador and Turkey.

Further, on the one hand, the probability of moving from low-to-low stock market performance is high among the upper-middle income countries except for Ecuador, which is 0.39 (Table 5). On the other hand, the probability of moving from low sock performance to high stock performance is highest in Ecuador (0.61), followed by South Africa (0.37), Brazil (0.16) and Peru (0.15). Meanwhile, the probability that the stock performance will deep from high performance is highest 
Table 3a. Unit Root Tests with Breaks with ADF

\begin{tabular}{|c|c|c|c|c|c|c|c|c|c|c|c|c|}
\hline & France & Germany & Italy & Spain & UK & Canada & Mexico & USA & China & India & Turkey & Japan \\
\hline Mean & 11805.4 & 13416.1 & 19166.0 & 17601.9 & 7146.3 & 2191.9 & 353.1 & 49037.1 & 30513.2 & 756.1 & 4446.0 & 690.9 \\
\hline Maximum & 147969 & 141397 & 172434 & 190839 & $1 \mathrm{E}+05$ & 31927 & 6297 & 709735 & 82692 & 14352 & 78546 & 9787 \\
\hline Minimum & 0 & 0 & 0 & 0 & 0 & 0 & 0 & 0 & 0 & 0 & 0 & 0 \\
\hline Skewness & 2.9 & 2.6 & 2.3 & 2.6 & 3.4 & 3.2 & 3.7 & 3.2 & 0.5 & 3.9 & 3.7 & 3.4 \\
\hline Kurtosis & 10.6 & 8.4 & 6.9 & 8.6 & 13.5 & 12.4 & 16.6 & 12.4 & 1.3 & 17.9 & 15.9 & 14.3 \\
\hline Jarque-Bera & 546.4 & 336.9 & 214.1 & 347.5 & 919.7 & 763.2 & 1430.1 & 763.9 & 21.0 & 1667.5 & 1306.6 & 1017.9 \\
\hline Probability & 0 & 0 & 0 & 0 & 0 & 0 & 0 & 0 & 0.0 & 0 & 0 & 0 \\
\hline \multirow[t]{2}{*}{ Observations } & 142 & 142 & 142 & 142 & 142 & 142 & 142 & 142 & 132 & 142 & 143 & 140 \\
\hline & South Korea & Nigeria & Morocco & South Africa & Tunisia & Brazil & Chile & Columbia & Ecuador & Peru & Australia & New Zealand \\
\hline Mean & 2247.9 & 28.5 & 155.2 & 210.1 & 64.4 & 1873.3 & 621.9 & 213.4 & 521.8 & 617.8 & 670.7 & 118.7 \\
\hline Maximum & 10635 & 493 & 2564 & 2783 & 864 & 33682 & 9252 & 3439 & 8225 & 13489 & 6533 & 1409 \\
\hline Minimum & 0 & 0 & 0 & 0 & 0 & 0 & 0 & 0 & 0 & 0 & 0 & 0 \\
\hline Skewness & 1.3 & 3.5 & 3.4 & 2.9 & 3.0 & 3.7 & 3.3 & 3.5 & 3.5 & 4.3 & 2.5 & 2.9 \\
\hline Kurtosis & 2.8 & 15.1 & 14.2 & 10.5 & 10.9 & 16.7 & 13.1 & 15.0 & 15.2 & 21.5 & 7.8 & 10.0 \\
\hline Jarque-Bera & 37.0 & 1129.8 & 995.4 & 515.2 & 571.3 & 1372.3 & 839.7 & 1085.9 & 1106.6 & 2482.6 & 280.5 & 488.9 \\
\hline Probability & 0 & 0 & 0 & 0 & 0 & 0 & 0 & 0 & 0 & 0 & 0 & 0 \\
\hline Observations & 136 & 138 & 140 & 138 & 138 & 135 & 138 & 134 & 133 & 143 & 138 & 141 \\
\hline
\end{tabular}

Note: Break dates are in parentheses while the statistics are ADF test statistics. Also, ${ }^{* * *},{ }^{* *},{ }^{*}$ indicates significant at $1 \%$, $5 \%$ and $10 \%$ level, respectively.

in Peru (0.85), followed by Brazil, Turkey and South Africa with probability $0.84,0.79$ and 0.63 , respectively. Lastly, the probability of remaining at high performance is highest in China (0.9), Mexico (0.9), Columbia (0.91) and Ecuador (0.70). Comparing the probability of being in the state of low/low and high/high across the uppermiddle income countries in Table 5 shows that China and Mexico stock cycles are likely to remain at origin for longer time when there is a shock. This is followed by Columbia. This is also indicated in their respective expected durations of being in the state of high and low stock market performances. This outcome suggests that South Africa stock market is most volatile, followed by Brazil and Peru while China, Mexico and Columbia are relatively less volatile.

Of the sampled low-middle income countries, COVID-19 deepens low stock market performance in Nigeria, India and Tunisia, while it is associated with the expansion portion of low stock market performance in Morocco. The asymmetric stock market cycles will be longer and negative for Nigeria and positive for India and Tunisia (Table 6). That is, stock market cycles will be longer on the threshold of low performance in Nige- ria but shorter for India and Tunisia. On the aggregate, stock market cycles of Morocco are symmetric but have been significantly influenced by COVID-19.

Moreover, among the low-middle income countries, the probability of being in the state of origin is highest in Nigeria with probability 0.96 and 0.94 of moving from low to another low performance and from high to another high performance between two periods, respectively. However, expected duration (approximately 28 days) of being in the state of low stock market performance is higher in Nigeria. The most volatile stock market among these economies is morocco, followed by India's and Tunisia's. Also, there have been significant switch in the stock market cycles of the low-middle income countries. While oil price and COVID-19 contributed significantly to the switch in India, it is COVID-19 in Morocco and Nigeria.

In sum, the probability of recovery (moving from low to high performance) of stock market is highest in Spain (0.88), India (0.77) and Ecuador (0.61). The results also suggested that investors' expectation formations in the stock market determines stock market performance given the significance of AR terms across estimations. 
Table 3a. Unit Root Tests with Breaks with ADF (Continued)

\begin{tabular}{|c|c|c|c|c|}
\hline & & Crude oil price & Stock market index & COVID-19 \\
\hline \multirow{3}{*}{ Morocco } & Level & $(05 / 03 / 2020)$ & $-6.62^{* * *}(06 / 03 / 2020)$ & $-38.43^{* * *}(27 / 03 / 2020)$ \\
\hline & 1st Difference & $-14.44^{* * *}(09 / 03 / 2020)$ & $-13.01^{* * *}(12 / 03 / 2020)$ & $-7.99^{* * *} \quad(08 / 04 / 2020)$ \\
\hline & Remarks & $\mathrm{I}(1)$ & $\mathrm{I}(0)$ & $\mathrm{I}(0)$ \\
\hline \multirow{3}{*}{ Tunisia } & Level & $(05 / 03 / 2020)$ & $-4.45^{* *}(11 / 03 / 2020)$ & $31.76^{* * *}(27 / 02 / 2020)$ \\
\hline & 1st Difference & $-14.44^{* * *}(09 / 03 / 2020)$ & $-6.56^{\star * \star}(31 / 01 / 2020)$ & $71.17^{* * *}(28 / 02 / 2020)$ \\
\hline & & $\mathrm{I}(1)$ & $\mathrm{I}(0)$ & $\mathrm{I}(0)$ \\
\hline
\end{tabular}

Note: Break dates are in parentheses while the statistics are ADF test statistics. Also, ${ }^{* * *}, * *,{ }^{*}$ indicates significant at $1 \%$, $5 \%$ and $10 \%$ level, respectively.

Table 3b. Unit Root Tests with Breaks with ADF

\begin{tabular}{|c|c|c|c|c|}
\hline & & Crude oil price & Stock market index & COVID-19 \\
\hline & Level & $10.82^{* * *}(25 / 2 / 2020)$ & $-5.00^{* * *}(04 / 03 / 2020)$ & $-30.91^{* * *}(25 / 03 / 2020)$ \\
\hline \multirow[t]{3}{*}{ Brazil } & 1st Difference & $-14.93^{\star * *}(05 / 03 / 2020)$ & $-17.69^{* * \star}(12 / 03 / 2020)$ & $-18.58^{* * *}(02 / 04 / 2020)$ \\
\hline & Remarks & $\mathrm{I}(0)$ & $\mathrm{I}(0)$ & $\mathrm{I}(0)$ \\
\hline & Level & $10.82^{* * *}(25 / 2 / 2020)$ & $(06 / 03 / 2020)$ & $-8.24^{* * *}(23 / 03 / 2020)$ \\
\hline \multirow[t]{3}{*}{ Chile } & 1st Difference & $-14.93^{* * *}(05 / 03 / 2020)$ & $-12.56^{* * *}(18 / 03 / 2020)$ & $-6.31^{* * *}(18 / 03 / 2020)$ \\
\hline & Remarks & $\mathrm{I}(0)$ & $\mathrm{I}(1)$ & $\mathrm{I}(0)$ \\
\hline & Level & $10.82^{\star * *}(25 / 2 / 2020)$ & $-10.67^{\star \star \star}(06 / 03 / 2020)$ & $-12.40^{* * *}(19 / 03 / 2020)$ \\
\hline \multirow[t]{3}{*}{ Columbia } & 1st Difference & $-14.93^{* * *}(05 / 03 / 2020)$ & $-11.08^{* * *}(26 / 03 / 2020)$ & $-50.42^{* * *}(17 / 03 / 2020)$ \\
\hline & Remarks & $\mathrm{I}(0)$ & $\mathrm{I}(0)$ & $\mathrm{I}(0)$ \\
\hline & Level & $10.82^{\star * *}(25 / 2 / 2020)$ & $-5.12^{\star * *}(21 / 11 / 2019)$ & $-9.29^{* * *}(23 / 03 / 2020)$ \\
\hline \multirow[t]{3}{*}{ Ecuador } & 1st Difference & $-14.93^{\star * *}(05 / 03 / 2020)$ & $-11.98^{\star * *}(11 / 2 / 2019)$ & $-8.88^{* * *}(20 / 03 / 2020)$ \\
\hline & Remarks & $\mathrm{I}(0)$ & $\mathrm{I}(0)$ & $\mathrm{I}(0)$ \\
\hline & Level & $10.82^{* * *}(25 / 2 / 2020)$ & $(27 / 02 / 2020)$ & $-10.53^{* * *}(25 / 02 / 2020)$ \\
\hline \multirow[t]{3}{*}{ Peru } & 1st Difference & $-14.93^{* * *}(05 / 03 / 2020)$ & $-4.62^{* * *}(12 / 03 / 2020)$ & $-15.09^{* * *}(05 / 03 / 2020)$ \\
\hline & Remarks & $\mathrm{I}(0)$ & $\mathrm{I}(1)$ & $\mathrm{I}(0)$ \\
\hline & Level & $10.82^{\star * *}(25 / 2 / 2020)$ & $-4.98^{* * *}(05 / 03 / 2020)$ & $(06 / 04 / 2020)$ \\
\hline \multirow[t]{3}{*}{ Australia } & 1st Difference & $-14.93^{* * *}(05 / 03 / 2020)$ & $-15.09^{* * *}(17 / 02 / 2020)$ & $-8.99^{* * *}(01 / 04 / 2020)$ \\
\hline & Remarks & $\mathrm{I}(0)$ & $\mathrm{I}(0)$ & $\mathrm{I}(1)$ \\
\hline & Level & $10.82^{* * *}(25 / 2 / 2020)$ & $(05 / 03 / 2020)$ & $(24 / 03 / 2020)$ \\
\hline \multirow[t]{2}{*}{ New Zealand } & 1st Difference & $-14.93^{* * *}(05 / 03 / 2020)$ & $-13.68^{\star * *}(15 / 04 / 2020)$ & $-7.19^{* * *}(22 / 01 / 2020)$ \\
\hline & Remarks & $\mathrm{I}(0)$ & $\mathrm{I}(1)$ & $\mathrm{I}(1)$ \\
\hline
\end{tabular}

Note: Break dates are in parentheses while the statistics are ADF test statistics. Also, ${ }^{* * *},{ }^{* *},{ }^{*}$ indicates significant at $1 \%$, $5 \%$ and $10 \%$ level, respectively.

\section{Conclusion, Policy lessons and Limitations of the Study}

The International Monetary Fund (IMF) pronounced COVID-19 unprecedented as the global economy faces worst recession in history. The issues that remain unclear is the time it will take countries to be back on recovery path and factors that may propel such recovery. Hence, this study investigated the timing of business cycles recovery among the sampled economies in global North and South. It equally examined for the nature of asymmetry in the business cycles of the sampled countries, and the impact of COVID-19 on such asymmetry. 
Table 4. High Income Economies

\begin{tabular}{|c|c|c|c|c|c|c|}
\hline Parameters & France (ss) & Germany (ms) & Spain (ss) & Italy (ms) & UK (ms) & Canada (ss) \\
\hline \multicolumn{7}{|l|}{ State 1} \\
\hline \multirow[t]{2}{*}{$\mu 1$} & 6980.054 & 9772.708 & 10511.14 & 28997.45 & 3978.590 & 9664.613 \\
\hline & $(34.73)^{\star * \star}$ & $(21.41)^{\star * *}$ & $(10.48)^{\star * *}$ & $(4.85)^{\star * *}$ & $(20.14)^{\star * *}$ & $(2.80)^{* * *}$ \\
\hline \multirow[t]{2}{*}{$\mathrm{D}$ (OilPrice) } & 5.995 & 9.377 & -11.686 & 22.073 & 5.015 & 5.115 \\
\hline & $(2.01)^{\star *}$ & $(2.18)^{\star *}$ & $(-1.36)$ & $(0.68)$ & $(1.07)$ & $(5.68)^{\star * *}$ \\
\hline \multirow[t]{2}{*}{ D(COVID-19) } & -0.108 & 3.739 & -0.090 & -0.035 & -0.001 & -3.545 \\
\hline & $(-8.48)^{\star * \star}$ & $(1.29)$ & $(-8.26)^{\star * *}$ & $(-1.14)$ & $(-0.22)$ & $(-12.97)^{\star \star *}$ \\
\hline \multirow[t]{2}{*}{$\sigma 1^{2}$} & 3.296 & 4.132 & 6.582 & 6.672 & 4.722 & 4.034 \\
\hline & $(23.06)^{\star \star \star}$ & $(54.33)^{* * *}$ & $(32.00)^{\star * *}$ & $(59.35)^{\star * *}$ & $(38.00)^{* * *}$ & $(55.30)^{* * *}$ \\
\hline \multicolumn{7}{|l|}{ State 2} \\
\hline \multirow[t]{2}{*}{$\mu 2$} & 6923.895 & 9320.249 & 10307.28 & 29317.41 & 4123.844 & 10142.61 \\
\hline & $(34.12)^{\star \star \star}$ & $(15.55)^{\star * \star}$ & $(10.16)^{* \star \star}$ & $(4.93)^{\star * *}$ & $(31.46)^{* * *}$ & $(2.94)^{\star \star \star}$ \\
\hline \multirow[t]{2}{*}{$\mathrm{D}$ (Oil Price) } & 14.986 & 8.762 & 9.559 & 39.435 & 2.125 & 48.494 \\
\hline & $(3.322)^{\star * *}$ & $(0.75)$ & $(2.62)^{* *}$ & $(3.02)^{* * *}$ & $(1.10)$ & $(3.71)^{* * *}$ \\
\hline \multirow[t]{2}{*}{ D(COVID-19) } & -0.020 & -0.014 & -0.088 & -0.310 & 2.193 & 0.063 \\
\hline & $(-2.75)^{\star \star}$ & $(-0.97)$ & $(-5.99)^{* * *}$ & $(-1.50)$ & $(0.95)$ & $(0.52)$ \\
\hline \multirow[t]{2}{*}{$\sigma 2^{2}$} & 5.126 & 5.621 & 4.255 & 5.088 & 3.327 & 6.585 \\
\hline & $(46.37)^{\star * \star}$ & $(45.25)^{\star * *}$ & $(51.81)^{* * *}$ & $(61.03)^{\star * *}$ & $(43.66)^{* * *}$ & $(46.12)^{* * *}$ \\
\hline \multirow[t]{3}{*}{$\operatorname{AR}(1)$} & 0.994 & 0.979 & 0.986 & 0.990 & 0.976 & 1.002 \\
\hline & $(84.10)^{\star * *}$ & $(62.15)^{* * *}$ & $(80.44)^{* * *}$ & $(67.74)^{* * *}$ & $(45.10)^{* * *}$ & $(781.06)^{* * *}$ \\
\hline & \multicolumn{6}{|c|}{ Transition Probabilities } \\
\hline P(Low|Low) & 0.62 & 0.99 & 0.12 & 0.96 & 0.99 & 0.78 \\
\hline P(Low $\mid$ High $)$ & 0.38 & 0.01 & 0.88 & 0.04 & 0.01 & 0.22 \\
\hline $\mathrm{P}$ (High|Low) & 0.61 & 0.01 & 0.12 & 0.02 & 0.01 & 0.78 \\
\hline \multirow[t]{2}{*}{ P(High|High) } & 0.38 & 0.99 & 0.88 & 0.98 & 0.99 & 0.22 \\
\hline & \multicolumn{6}{|c|}{ Expected Durations } \\
\hline State 1 (low) & 2.61 & 163.55 & 1.14 & 27.74 & 97.17 & 4.60 \\
\hline State 2 (high) & 1.62 & 97.49 & 8.04 & 53.92 & 163.02 & 1.28 \\
\hline \multirow[t]{2}{*}{ Log-likelhood } & -802.79 & -799.83 & -837.17 & -947.98 & -689.25 & -869.95 \\
\hline & \multicolumn{6}{|c|}{ Hypotheses Testing (with t- statistics) } \\
\hline$\mu 0=\mu 1$ & $5.950^{* * *}$ & 1.444 & $3.970^{* * *}$ & $-1.787^{\star}$ & -1.038 & $-14.858^{* * *}$ \\
\hline Oilp1= Oilp2 & -1.605 & 0.049 & $-2.193^{* *}$ & -0.492 & 0.571 & $-3.312^{* * *}$ \\
\hline COVID-19_1= & $-9.815^{\star * *}$ & 1.290 & -0.176 & 1.460 & -0.948 & $-12.818^{\star * *}$ \\
\hline \multicolumn{7}{|l|}{ COVID-19_2 } \\
\hline$\sigma 12=\sigma 22$ & $-11.294^{* * *}$ & $-10.105^{\star * *}$ & $10.745^{* * *}$ & $11.481^{* * *}$ & $9.447^{* * *}$ & $-15.987^{\star * *}$ \\
\hline Inverted AR & 0.99 & 0.98 & 0.99 & 0.99 & 0.98 & 0.99 \\
\hline \multicolumn{7}{|l|}{ roots } \\
\hline Obs & 137 & 133 & 133 & 133 & 133 & 133 \\
\hline
\end{tabular}

Note: $z$-statistics in parentheses. Also, ${ }^{* * *},{ }^{* *},{ }^{*}$ indicates significant at $1 \%, 5 \%$ and $10 \%$ level, respectively. MS and SS represents models estimated with Markov switching and simple switching, respectively. 
Table 4. High Income Economies (Continued)

\begin{tabular}{|c|c|c|c|c|c|c|}
\hline Parameters & Japan (ms) & $\begin{array}{c}\text { South Korea } \\
\text { (ss) }\end{array}$ & USA(ss) & Chile (ss) & $\begin{array}{c}\text { New Zealand } \\
\text { (ms) }\end{array}$ & $\begin{array}{c}\text { Australia } \\
\text { (ms) }\end{array}$ \\
\hline \multicolumn{7}{|l|}{ State 1} \\
\hline \multirow[t]{2}{*}{$\mu 1$} & 2205.53 & 2180.40 & 3403.871 & 21908.93 & -1582.606 & 7186.736 \\
\hline & $(6.90)^{* * *}$ & $2(8.44)^{* * *}$ & $(29.01)^{\star * *}$ & $(19.18)^{* * *}$ & $(-1.29)$ & $(14.02)^{* * *}$ \\
\hline \multirow[t]{2}{*}{$\mathrm{D}$ (OilPrice) } & 4.187 & 1.589 & 0.717 & $34.948(2.77)^{\star *}$ & 0.351 & 31.183 \\
\hline & $(1.62)$ & $(0.90)$ & $(2.70)^{\star *}$ & & $(0.21)$ & $(2.77)^{\star *}$ \\
\hline \multirow[t]{2}{*}{ D(COVID-19) } & -0.019 & -0.017 & -0.004 & 0.141 & 0.125 & 0.026 \\
\hline & $(-0.41)$ & $(-1.16)$ & $(-6.05)^{* * *}$ & $(0.602)$ & $(1.12)$ & $(0.16)$ \\
\hline \multirow[t]{2}{*}{$\sigma 1^{2}$} & 4.225 & 3.459 & 2.481 & 5.685 & 3.709 & 5.352 \\
\hline & $(38.16)^{\star * \star}$ & $(30.72)^{* * *}$ & $(18.06)^{\star * *}$ & $(64.484)^{\star * \star}$ & $(28.71)^{* * *}$ & $(37.28)^{* * *}$ \\
\hline \multicolumn{7}{|l|}{ State 2} \\
\hline \multirow[t]{2}{*}{$\mu 2$} & 2228.330 & 2177.833 & 3385.886 & 21816.61 & -1576.898 & 7226.529 \\
\hline & $(6.98)^{* * *}$ & $(8.48)^{* * *}$ & $(28.86)^{* * *}$ & $(18.256)^{\star * *}$ & $(-1.28)$ & $(14.05)^{* * *}$ \\
\hline \multirow[t]{2}{*}{ D(Oil Price) } & -0.906 & 4.863 & 1.610 & 11.666 & 0.429 & -7.271 \\
\hline & $(-1.18)$ & $(2.53)^{\star \star}$ & $(5.27)^{\star \star \star}$ & $(-0.254)$ & $(0.56)$ & $(-2.81)^{\star \star}$ \\
\hline \multirow[t]{2}{*}{ D(COVID-19) } & -0.412 & -0.527 & 0.001 & -17.076 & -2.543 & 0.339 \\
\hline & $(-4.48)^{\star * *}$ & $(-8.86)^{\star * *}$ & $(1.87)^{*}$ & $(-2.30)^{\star *}$ & $(-4.33)^{* * *}$ & $(3.05)^{* * *}$ \\
\hline \multirow[t]{2}{*}{$\sigma 2^{2}$} & 2.275 & 2.892 & 4.722 & 7.00 & 2.367 & 3.893 \\
\hline & $(26.17)^{\star * *}$ & $(18.31)^{* * *}$ & $(39.08)^{* * *}$ & $(26.189)^{\star * *}$ & $(26.10)^{* * *}$ & $(51.06)^{* * *}$ \\
\hline \multirow[t]{3}{*}{$\operatorname{AR}(1)$} & 0.990 & 0.988 & 0.983 & 0.971 & 0.987 & 0.986 \\
\hline & $(768.29)^{\star \star \star}$ & $(75.56)^{* * *}$ & $(117.14)^{* * *}$ & $(87.76)^{* * *}$ & $(263.70)^{\star * \star}$ & $(89.17)^{* * *}$ \\
\hline & \multicolumn{6}{|c|}{ Transition Probabilities } \\
\hline $\mathrm{P}$ (Low $\mid$ Low $)$ & 0.92 & 0.66 & 0.65 & 0.91 & 0.95 & 0.95 \\
\hline P(Low $\mid$ High) & 0.08 & 0.34 & 0.35 & 0.09 & 0.05 & 0.05 \\
\hline P(High|Low) & 0.05 & 0.66 & 0.65 & 0.91 & 0.02 & 0.01 \\
\hline \multirow[t]{2}{*}{ P(High|High) } & 0.95 & 0.34 & 0.35 & 0.09 & 0.98 & 0.99 \\
\hline & \multicolumn{6}{|c|}{ Expected Durations } \\
\hline State 1 (low) & 13.21 & 2.93 & 2.86 & 11.04 & 20.53 & 21.72 \\
\hline State 2 (high) & 21.23 & 1.52 & 1.54 & 1.1 & 46.91 & 107.53 \\
\hline \multirow[t]{2}{*}{ Log-likelhood } & -609.52 & -591.21 & -684.15 & -892.628 & -552.32 & -718.69 \\
\hline & \multicolumn{6}{|c|}{ Hypotheses Testing (with t- statistics) } \\
\hline$\mu 0=\mu 1$ & $-2.986^{* * *}$ & 0.467 & $3.305^{* * *}$ & 0.50 & -0.214 & -0.558 \\
\hline Oilp1= Oilp2 & $1.838^{*}$ & -1.068 & $-2.415^{\star *}$ & 0.96 & -0.042 & $3.330^{* * *}$ \\
\hline COVID-19_1= & $5.398^{* * *}$ & $8.248^{\star * *}$ & $-9.022^{* * *}$ & $2.32^{* *}$ & $4.581^{* * *}$ & $-1.714^{*}$ \\
\hline \multicolumn{7}{|l|}{ COVID-19_2 } \\
\hline$\sigma 12=\sigma 22$ & $14.096^{* * *}$ & $2.600^{* *}$ & $-14.184^{* * *}$ & $-4.91^{\star * *}$ & $8.600^{* * *}$ & $8.949^{* * *}$ \\
\hline Inverted AR & 0.99 & 0.99 & 0.98 & 0.98 & 0.99 & 0.99 \\
\hline \multicolumn{7}{|l|}{ roots } \\
\hline Obs & 133 & 122 & 133 & 125 & 130 & 126 \\
\hline
\end{tabular}


Table 5. Upper-Middle Income Countries

\begin{tabular}{|c|c|c|c|c|c|c|}
\hline Parameters & Brazil (ss) & China (ms) & $\begin{array}{c}\text { Columbia } \\
\text { (ms) }\end{array}$ & Ecuador (ms) & Peru (ss) & $\begin{array}{c}\text { South Africa } \\
\text { (ss) }\end{array}$ \\
\hline \multicolumn{7}{|l|}{ State 1} \\
\hline \multirow[t]{2}{*}{$\mu 1$} & 113959.5 & 10803.78 & 1604.368 & 1369.869 & 115.173 & 55358.62 \\
\hline & $(19.58)^{* * *}$ & $(9.52)^{\star \star \star}$ & $(29.05)^{\star \star \star}$ & $(467.15)^{\star * *}$ & $(6.76)^{* * \star}$ & $(7.90)^{\star \star \star}$ \\
\hline \multirow[t]{2}{*}{ D(OilPrice) } & 96.840 & 21.751 & 0.035 & 0.870 & -0.013 & 32.564 \\
\hline & $(1.43)$ & $(2.59)^{\star \star \star}$ & $(0.12)$ & $(3.05)^{* * *}$ & $(-0.38)$ & $(0.96)$ \\
\hline \multirow[t]{2}{*}{ D(COVID-19) } & -5.911 & 0.011 & -0.094 & 0.009 & 0.000 & -102.541 \\
\hline & $(-4.87)^{\star * *}$ & $(0.93)$ & $(-1.81)^{\star}$ & $(2.75)^{\star \star}$ & $(0.75)$ & $(-6.67)^{* * *}$ \\
\hline \multirow[t]{2}{*}{$\sigma 1^{2}$} & 6.879 & 5.338 & 2.876 & 2.624 & 0.755 & 5.876 \\
\hline & $(72.88)^{* * *}$ & $(51.25)^{* * *}$ & $(37.91)^{\star * \star}$ & $(20.09)^{\star * *}$ & $(7.18)^{\star * *}$ & $(44.55)^{\star * *}$ \\
\hline \multicolumn{7}{|l|}{ State 2} \\
\hline \multirow[t]{2}{*}{$\mu 2$} & 111965.1 & 10971.80 & 1530.051 & 1369.743 & 112.322 & 55198.44 \\
\hline & $(19.36)^{\star * *}$ & $(9.26)^{\star * \star}$ & $(14.60)^{* * *}$ & $(465.70)^{\star * *}$ & $(6.44)^{* * *}$ & $(7.72)^{* * *}$ \\
\hline \multirow[t]{2}{*}{ D(Oil Price) } & 150.669 & -6.780 & 4.869 & -0.014 & 0.199 & 36.65 \\
\hline & $(6.80)^{* * *}$ & $(-0.85)$ & $(1.44)$ & $(-0.65)$ & $(3.10)^{\star \star \star}$ & $(0.83)$ \\
\hline \multirow[t]{2}{*}{ D(COVID-19) } & -3.551 & 0.232 & -2.908 & -0.005 & 0.089 & -5.215 \\
\hline & $(-3.91)^{\star * *}$ & $(1.00)$ & $(-1.92)^{\star}$ & $(-3.04)^{* * *}$ & $(3.03)^{* * *}$ & $(-1.03)$ \\
\hline \multirow[t]{2}{*}{$\sigma 2^{2}$} & 8.819 & 4.517 & 4.312 & 0.101 & 2.150 & 7.302 \\
\hline & $(48.29)^{* * *}$ & $(49.68)^{* * *}$ & $(18.64)^{* * \star}$ & $(0.82)$ & $(11.28)^{* * *}$ & $(53.19)^{\star * *}$ \\
\hline \multirow[t]{3}{*}{$\operatorname{AR}(1)$} & 0.977 & 0.982 & 0.965 & 0.992 & 0.984 & 0.989 \\
\hline & $(79.47)^{* * *}$ & $(48.73)^{* * *}$ & $(75.54)^{* * \star}$ & $(221.82)^{\star * *}$ & $(106.16)^{\star * *}$ & $(40.75)^{\star * \star}$ \\
\hline & \multicolumn{6}{|c|}{ Transition Probabilities } \\
\hline P(Low|Low) & 0.84 & 0.99 & 0.99 & 0.39 & 0.85 & 0.63 \\
\hline P(Low $\mid$ High $)$ & 0.16 & 0.01 & 0.01 & 0.61 & 0.15 & 0.37 \\
\hline $\mathrm{P}$ (High|Low) & 0.84 & 0.01 & 0.09 & 0.30 & 0.85 & 0.63 \\
\hline \multirow[t]{2}{*}{$\mathrm{P}($ High|High $)$} & 0.16 & 0.99 & 0.91 & 0.70 & 0.15 & 0.37 \\
\hline & \multicolumn{6}{|c|}{ Expected Durations } \\
\hline State 1 (low) & 6.40 & 112.92 & 129.48 & 1.65 & 6.46 & 2.72 \\
\hline State 2 (high) & 1.19 & 129.15 & 10.68 & 3.28 & 1.18 & 1.58 \\
\hline \multirow[t]{2}{*}{ Log-likelhood } & -1054.69 & -777.94 & -508.30 & -325.05 & -358.48 & -1020.82 \\
\hline & \multicolumn{6}{|c|}{ Hypotheses Testing (with t- statistics) } \\
\hline$\mu 0=\mu 1$ & $3.806^{* * *}$ & -0.588 & 0.858 & 0.372 & $2.350^{\star *}$ & 0.768 \\
\hline Oilp1= Oilp2 & $-0.763^{\star * *}$ & $2.451^{\star *}$ & -1.394 & $3.081^{* * *}$ & $-2.994^{\star * *}$ & -0.069 \\
\hline COVID-19_1= & $-4.608^{\star * *}$ & -0.949 & $1.858^{*}$ & $5.488^{\star * *}$ & $-3.018^{\star * *}$ & -6.419 \\
\hline \multicolumn{7}{|l|}{ COVID-19_2 } \\
\hline$\sigma 12=\sigma 22$ & $-9.899^{* * *}$ & $5.901^{* * *}$ & $-5.861^{* * *}$ & $15.555^{\star * \star}$ & $-7.347^{\star * *}$ & $-8.665^{\star * *}$ \\
\hline Inverted AR & 0.98 & 0.98 & 0.97 & 0.99 & 0.98 & 0.99 \\
\hline \multicolumn{7}{|l|}{ roots } \\
\hline Obs & 118 & 123 & 113 & 115 & 136 & 126 \\
\hline
\end{tabular}

Note: $z$-statistics in parentheses. Also, ${ }^{* * *},{ }^{* *},{ }^{*}$ indicates significant at $1 \%, 5 \%$ and $10 \%$ level, respectively. MS and SS represents models estimated with Markov switching and simple switching, respectively. 
Table 5. Upper-Middle Income Countries (Continued)

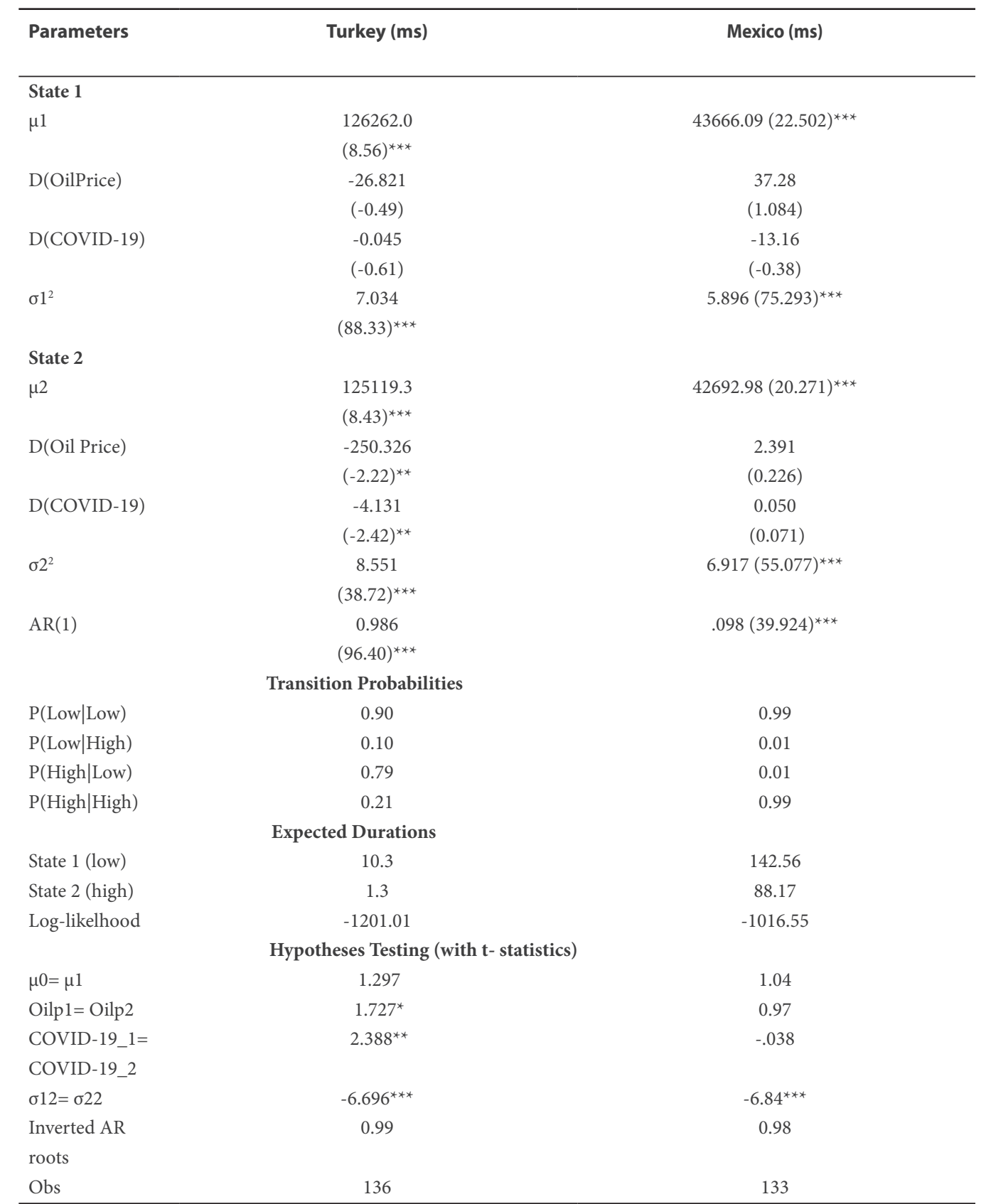

Note: $z$-statistics in parentheses. Also, ${ }^{* *},{ }^{* *},{ }^{*}$ indicates significant at $1 \%, 5 \%$ and $10 \%$ level, respectively. MS and SS represents models estimated with Markov switching and simple switching, respectively. 
Table 6. Lower-Middle Income Countries

\begin{tabular}{|c|c|c|c|c|}
\hline Parameters & India (ss) & Morocco (ss) & Nigeria (ms) & Tunisia (ss) \\
\hline \multicolumn{5}{|l|}{ State 1} \\
\hline \multirow[t]{2}{*}{$\mu 1$} & 38738.75 & 11681.60 & 25060.10 & 6971.184 \\
\hline & $(27.75)^{\star * \star}$ & $(46.07)^{* * *}$ & $(20.72)^{\star * *}$ & $(109.82)^{* * *}$ \\
\hline \multirow[t]{2}{*}{ D(OilPrice) } & 161.35 & 11.216 & 3.108 & -4.007 \\
\hline & $(6.82)^{\star \star \star *}$ & $(2.800)^{\star \star}$ & $(0.39)$ & $(-2.78)^{\star \star}$ \\
\hline \multirow[t]{2}{*}{ D(COVID-19) } & -0.626 & 452.039 & -524.242 & -0.636 \\
\hline & $(-4.04)^{\star * \star}$ & $(5.82)^{* * *}$ & $(-4.48)^{* * *}$ & $(-5.27)^{\star * \star}$ \\
\hline \multirow[t]{2}{*}{$\sigma 1^{2}$} & 7.165 & 3.576 & 4.719 & 4.434 \\
\hline & $(49.04)^{* * *}$ & $(21.93)^{* * *}$ & $(50.96)^{* * *}$ & $(29.80)^{\star * *}$ \\
\hline \multicolumn{5}{|l|}{ State 2} \\
\hline \multirow[t]{2}{*}{$\mu 2$} & 39161.21 & 11702.09 & 24625.85 & 6965.33 \\
\hline & $(28.93)^{* * *}$ & $(46.88)^{* * *}$ & $(20.35)^{\star * *}$ & $(105.82)^{\star * *}$ \\
\hline \multirow[t]{2}{*}{ D(Oil Price) } & 49.788 & 13.134 & -9.422 & -0.592 \\
\hline & $(2.58)^{\star *}$ & $(2.07)^{\star *}$ & $(-0.43)$ & $(-0.55)$ \\
\hline \multirow[t]{2}{*}{ D(COVID-19) } & -2.299 & 0.164 & -6.160 & -0.435 \\
\hline & $(-6.96)^{\star \star \star}$ & $(0.37)$ & $(-1.28)$ & $(-2.81)^{\star \star}$ \\
\hline \multirow[t]{2}{*}{$\sigma 2^{2}$} & 5.413 & 5.405 & 6.086 & 2.520 \\
\hline & $(52.39)^{* * *}$ & $(49.24)^{* * *}$ & $(48.07)^{* * *}$ & $(17.45)^{\star * \star}$ \\
\hline \multirow[t]{3}{*}{$\operatorname{AR}(1)$} & 0.976 & 1.005 & 0.978 & 0.988 \\
\hline & $(81.23)^{* * *}$ & $(73.74)^{* * *}$ & $(84.09)^{* * *}$ & $(75.25)^{\star * \star}$ \\
\hline & \multicolumn{4}{|c|}{ Transition Probabilities } \\
\hline P(Low|Low) & 0.23 & 0.50 & 0.96 & 0.30 \\
\hline P(Low $\mid$ High $)$ & 0.77 & 0.50 & 0.04 & 0.70 \\
\hline $\mathrm{P}$ (High|Low) & 0.23 & 0.50 & 0.06 & 0.30 \\
\hline \multirow[t]{2}{*}{$\mathrm{P}($ High $\mid$ High $)$} & 0.77 & 0.50 & 0.94 & 0.70 \\
\hline & \multicolumn{4}{|c|}{ Expected Durations } \\
\hline State 1 (low) & 1.29 & 2.00 & 27.47 & 1.43 \\
\hline State 2 (high) & 4.44 & 2.00 & 15.80 & 3.30 \\
\hline \multirow[t]{2}{*}{ Log-likelhood } & -1009.65 & -796.36 & -860.71 & -590.53 \\
\hline & \multicolumn{4}{|c|}{ Hypotheses Testing (with t- statistics) } \\
\hline$\mu 0=\mu 1$ & $-4.443^{\star * *}$ & -1.482 & $4.913^{* * *}$ & 0.907 \\
\hline Oilp1= Oilp2 & $3.668^{* * *}$ & -0.249 & 0.55 & $-1.789^{*}$ \\
\hline COVID-19_1= & $7.389^{\star * *}$ & $5.814^{* * *}$ & $-4.422^{\star * *}$ & -1.332 \\
\hline \multicolumn{5}{|l|}{ COVID-19_2 } \\
\hline$\sigma 12=\sigma 22$ & $10.577^{\star * *}$ & $-10.618^{\star * *}$ & $-8.604^{* * *}$ & $11.635^{\star * *}$ \\
\hline Inverted AR & 0.98 & 1.0 & 0.98 & 0.99 \\
\hline \multicolumn{5}{|l|}{ roots } \\
\hline Obs & 133 & 127 & 128 & 123 \\
\hline
\end{tabular}

Note: $\mathrm{z}$-statistics in parentheses. Also, ${ }^{* * *},{ }^{* *},{ }^{*}$ indicates significant at $1 \%, 5 \%$ and $10 \%$ level, respectively. MS and SS represents models estimated with Markov switching and simple switching, respectively. 
The results showed a significant switch in the business cycles of countries due to COVID-19. Among the 12 countries (representing $50 \%$ of the entire sample) estimated with Markov switching model, COVID-19 has a large negative asymmetric effect only on Nigeria. That is, the negative impact of COVID-19 will be lingered on Nigeria stock market. Other countries in these category are China, Columbia, Ecuador, Turkey and Mexico among Middle-income countries and Italy, UK, Germany, Japan, New Zealand and Australia among high income countries. Specifically, the expected duration of being in the state of low stock market performance in Nigeria will be about 27days, while the expected duration of being in the state of high stock market performance will be about 15days for a complete stock market cycle. The implication of the outcome is that the net loss of uppermiddle-income and high-income countries in the long term will be lesser than lower-middle-income countries such as Nigeria. In the estimations utilising simple switching model, COVID-19 has a short negative asymmetric impact on Brazil, Peru, France, Canada and USA, while it has short positive asymmetric effect on India, Morocco, South Korea and Chile. By implication, potential gains will be greater than potential losses in the later countries in the short run. The opposite is the case in the former countries.

In terms of policy, rebound in oil price will be a quick fix to long- and short-term downward spiral in stock market performance, and by extension the business cycles, among significant proportion of sampled countries. Hence, recent moves to reduce crude oil production and export glut by the OPEC to improve crude oil prices could be a step in the right direction. Also, reduction in market risks associated with COVID-19 will go a long way to enhance the stock market recovery and revive investors' confidence in the sampled economies. One of the ways of going about this will be to invest in critical COVID-19 targeted health infrastructure such as testing, tracing and containment, especially among lower income countries. Also, investment in vaccine development that could help to restore global health will go a long way to fully kick-start the engine of global economic growth.
Further, in order to minimize the possible negative impact of COVID-19 on stock performance countries should prepare preventive remedies, especially at the national borders, by putting in place adequate health check to minimize importation and spread of such human-to-human transmissible infections. Also, an effective, timely and efficient emergency response can reduce the spread and mortality associated with infectious decreases such as COVID-19. That is, since severity of the outbreak is associated with severity of the economic and stock market impact, timely response will reduce the economic impacts in the case of unavoidable outbreak. This cannot be possible without adequate information and transparency by national governments on early warning notification of an infectious diseases outbreaks. Hence, there is a need to increase investment in infectious diseases surveillance.

Besides, one of the effects of COVID-19 is disruption to global value chains which affected companies listed on the stock exchange across countries. It is obvious that the disruptions to value chains is a policy response, in the forms of movement restrictions, borders closure and social distancing, to limit spread of COVID-19 and not necessarily the natural reaction of the market to the outbreak of COVID-19. Hence, a better policy would rather be strict enforcement of the use of protective equipment such as face masks, face shields, and hand sanitisers in public places, which would have limited the spread, rather than just blanket lockdown, most of which are devoid of adequate testing and tracing especially among the developing countries.

This study significantly associated stock market with business cycles of the sampled economies for the period of 7 months. We understand that business cycles analysis requires data for a longer period of time and more series. However, COVID-19 is a recent event and it will be unconvincing combining the event that started around December2019/January2020 with business cycles which its assessment requires many years. We have used daily data which was available for all the series considered. Meanwhile future studies can construct the actual business cycles of these economies with other components such as stock market industrial productivity, unemployment and inventories for a longer period of time. 


\section{References}

Adam, K. \& Merkel, S. (2019). Stock price cycles and business cycles (Working Paper Series No. 2316). European Central Bank. https://www.ecb.europa. eu/pub/pdf/scpwps/ecb.wp2316 4effe6153e. en.pdf

Baker, S. R., Bloom, N., Davis, S. J., Kost, K. J., Sammon, M. C., \& Viratyosin, T. (2020). The unprecedented stock market impact of COVID-19 (Working Paper No. 26945). National Bureau of Economic Research http://www.nber.org/papers/w26945

Chauvet, M. (2001). Stock market fluctuations and the business cycle. SSRN Electronic Journal. https://doi.org/10.2139/ssrn.283793

Chen, M. H., Jang, S. S., \& Kim, W. G. (2007). The impact of the SARS outbreak on Taiwanese hotel stock performance: An event-study approach. International Journal of Hospitality Management, 26(1), 200-212. https://doi.org/10.1016/j. ijhm.2005.11.004

Chen, M. P., Lee, C. C., Lin, Y. H., \& Chen, W. Y. (2018). Did the SARS epidemic weaken the integration of Asian stock markets? Evidence from smooth time-varying cointegration analysis. Economic research-Ekonomska istraživanja, 31(1), 908-926. https://doi.org/10.1080/133167 7X.2018.1456354

Diebold, F. X., \& Rudebusch, G. D. (1991). Forecasting output with the composite leading index: A real-time analysis. Journal of the American Statistical Association, 86(415), 603-610. https://doi. org/10.2307/2290388

Estrella, A., \& Mishkin, F. S. (1998). Predicting US recessions: Financial variables as leading indicators. Review of Economics and Statistics, 80(1), 45-61. https://doi.org/10.1162/003465398557320

Fendel, R., Mai, N., \& Mohr, O. (2019). Predicting recessions using term spread at the zero lower bound: The case of the euro area. VOX, CEPR Policy Portal. https://voxeu.org/article/predicting-recessions-using-term-spread-zero-lowerbound.

Haltmaier, J. (2008). Predicting cycles in economic activity (Board of Governors of the Federal Reserve System International Finance Discussion Papers No. 926). https://doi.org/10.2139/ssrn.1118978

Hamilton, J. D. (1989). A new approach to the economic analysis of nonstationary time series and the business cycle. Econometrica, 57(2), 357-384. https://doi.org/10.2307/1912559
Hamilton, J. D., \& Lin, G. (1996). Stock market volatility and the business cycle. Journal of Applied Econometrics, 11(5), 573-593. https://doi.org/10.1002/ (SICI) 1099-1255(199609)11:5<573::AIDJAE413>3.0.CO;2-T

He, Q., Liu, J., Wang, S., \& Yu, J. (2020). The impact of COVID-19 on stock markets. Economic and Political Studies, 8(3), 275288. https://doi.org/10.1080/20954816.2020. 1757570

International Civil Aviation Organization of the United Nations. (2020). Effects of novel coronavirus (COVID-19) on civil aviation: Economic impact analysis. https://www.icao. int/sustainability/Documents/COVID-19/ ICAO_Coronavirus_Econ_Impact.pdf

International Labour Organisation. (2020). ILO Monitor: COVID-19 and the world of work. Updated estimates and analysis. https:// www.ilo.org/wcmsp5/groups/public/@dgreports/@dcomm/documents/briefingnote/ wcms_743146.pdf

Joo, H., Maskery, B. A., Berro, A. D., Rotz, L. D., Lee, Y. K., \& Brown, C. M. (2019). Economic impact of the 2015 MERS outbreak on the Republic of Korea's tourism-related industries. Health security, 17(2), 100-108. https:// doi.org/10.1089/hs.2018.0115

Jung, E., \& Sung, H. (2017). The influence of the Middle East respiratory Syndrome outbreak on online and offline markets for retail sales. Sustainability, 9(3), 411. https://doi. org/10.3390/su9030411

Kaufmann, S. (2002). Is there an asymmetric effect of monetary policy over time? In J. D. Hamilton, \& B. Raj (Eds.), Advances in Markov-Switching Models (pp. 137-157). Physica, Heidelberg. https://doi.org/10.1007/978-3642-51182-0_7

Keogh-Brown, M. R., \& Smith, R. D. (2008). The economic impact of SARS: how does the reality match the predictions? Health Policy, 88(1), 110-120. https://doi.org/10.1016/j. healthpol.2008.03.003

Kim, C., \& Nelson, C. R. (1999). Friedman's plucking model of business fluctuations: Tests and estimates of permanent and transitory components. Journal of Money, Credit and Banking, 31,317-334. https://doi.org/10.2307/2601114 
Lee J. W., \& McKibbin, W. J. (2004). Estimating the global economic costs of SARS. In S. Knobler, A. Mahmoud, S. Lemon, A. Mack, L. Sivitz, \& K. Oberholtzer (Eds.), Learning from SARS: Preparing for the next disease outbreak: Workshop summary (pp. 92-109). National Academies Press. https://www. ncbi.nlm.nih.gov/books/NBK92473/

Liu, H., Manzoor, A., Wang, C., Zhang, L., \& Manzoor, Z. (2020). The COVID-19 outbreak and affected countries stock markets response. International Journal of Environmental Research and Public Health, 17(8), 1-19. https://doi.org/10.3390/ ijerph 17082800

Muchaonyerwa, F., \& Choga, I. (2015). Business cycles and stock market performance in South Africa. Corporate Ownership \& Control, 12(3): 84-93. http://doi.org/10.22495/ cocv12i $3 \mathrm{p} 8$

Morley, J. (2019). The business cycle: Periodic pandemic or rollercoaster ride? International Journal of Economic Policy Studies, 13(2), 425-431. https://doi.org/10.1007/s42495019-00023-z

Nordhaus, W. D. (1975). The political business cycle. The Review of Economic Studies, 42(2), 169-190. https://doi.org/10.2307/2296528

Olakojo, S.A. (2018). Foreign trade and international financial flows: Implications for economic stability in the selected ECOWAS countries. Iranian Economic Review, 22(1), 63-103. https://doi.org/10.22059/ IER.2018.65352

Petrosillo, N., Viceconte, G., Ergonul, O., Ippolito, G., \& Petersen, E. (2020). COVID-19, SARS and MERS: are they closely related? Clinical Microbiology and Infection, 26(6), 729-734. https://doi.org/10.1016/j. cmi.2020.03.026

Qiu, W., Chu, C., Mao, A., \& Wu, J. (2018). The impacts on health, society, and economy of SARS and H7N9 outbreaks in China: A case comparison study. Journal of Environmental and Public Health, 2018, 1-7. https:// doi.org/10.1155/2018/2710185

Sansa, N. A. (2020). The impact of the COVID-19 on the financial markets: Evidence from China and USA. Electronic Research Journal of Social Sciences and Humanities, 2(2), 29-39. https://doi.org/10.2139/ ssrn. 3567901
Siegel, J. J. (1991). The behaviour of stock returns around N.B.E.R turning points: An overview (Weiss Center Working Paper). Wharton School - Weiss Center for International Financial Research. https://ideas.repec.org/p/ $\mathrm{fth} /$ pennif/5-91.html

United Nations Conference on Trade and Development. (2020). Coronavirus: Can policymakers avert a trillion-dollar crisis? https://unctad.org/en/pages/newsdetails. aspx? OriginalVersionID $=2300$

United Nations Industrial Development Organisation. (2020). World manufacturing production. Statistics for Quarter 1. https://www.unido.org/sites/default/files/ files/2020-06/World_manufacturing_production_2020_Q1.pdf

United States Energy Information Administration. (2020). Europe Brent Spot Price. https:// www.eia.gov/dnav/pet/hist/rbrteD.htm

Van Norden, S., \& Vigfusson, R. (1996). Regime-switching models: A guide to the Bank of Canada gauss procedures (Staff Working Paper No. 1996-3). Bank of Canada. https:// www.bankofcanada.ca/1996/01/workingpaper-1996-3/

Worldometer. (2020). Total coronavirus cases by countries. https://www.worldometers.info/ coronavirus/countries-where-coronavirushas-spread/

Zarnowitz, V. (1985). Recent work on business cycles in historical perspective: A review of theories and evidence. Journal of Economic Literature 23(2), 523-580. https://doi. org/10.3386/w1503 